Article

\title{
Data Mining and Validation of AMPK Pathway as a Novel Candidate Role Affecting Intramuscular Fat Content in Pigs
}

\author{
Chaogang Yao ${ }^{+}\left(\mathbb{D}\right.$, Daxin Pang ${ }^{\dagger}$, Chao Lu, Aishi Xu, Peixuan Huang, Hongsheng Ouyang * and \\ Hao Yu *(D) \\ Jilin Provincial Key Laboratory of Animal Embryo Engineering, College of Animal Sciences, Jilin University, \\ Changchun 130062, China; yaocg13@mails.jlu.edu.cn (C.Y.); pdx@jlu.edu.cn (D.P.); \\ swjs092408147@163.com (C.L.); xuaishi2008@aliyun.com (A.X.); huangpx16@mails.jlu.edu.cn (P.H.) \\ * Correspondence: ouyh@jlu.edu.cn (H.O.); yu_hao@jlu.edu.cn (H.Y.); \\ Tel.: +86-0431-8783-6175 (H.O.); +86-0431-8783-6176 (H.Y.) \\ + These authors contributed equally to this work.
}

Received: 25 March 2019; Accepted: 27 March 2019; Published: 1 April 2019

Simple Summary: Intramuscular fat (IMF) is increasingly being recognized as a key meat trait in the modern pork industry. The aims of this research were to identify potential signaling pathways associated with IMF content in the longissimus dorsi (LD) muscle of different pig breeds and investigate the gene expression levels in the screened signaling pathways. Our results indicated that the AMPK signaling pathway may be related to IMF deposition in the LD muscle of pigs. The results of qRT-PCR analysis showed that the expression of ten key hub genes (AMPK, ADIPOR1, ADIPOR2, $L K B 1, C A M K K \beta, C P T 1 A, C P T 1 B, P G C-1 \alpha, C D 36$, and ACC1) differed between the LD muscle of Min and Large White pigs. The protein expression levels of AMPK, LKB1, CaMKK2, CPT1A, and ACC1 were similar to the genes expression patterns in the LD muscle of Large White pigs. The results of this study provide novel insights into the regulatory function of the AMPK signaling pathway in relation to the IMF content in the LD muscle of different pigs.

\begin{abstract}
Intramuscular fat (IMF) is an important economic trait for pork quality and a complex quantitative trait regulated by multiple genes. The objective of this work was to investigate the novel transcriptional effects of a multigene pathway on IMF deposition in the longissimus dorsi (LD) muscles of pigs. Potential signaling pathways were screened by mining data from three gene expression profiles in the Gene Expression Omnibus (GEO) database. We designed quantitative real-time reverse transcription-polymerase chain reaction (qRT-PCR) arrays for the candidate signaling pathways to verify the results in the LD muscles of two pig breeds with different IMF contents (Large White and Min). Western blot analysis was used to detect the expression levels of several candidate proteins. Our results showed that the AMPK signaling pathway was screened via bioinformatics analysis. Ten key hub genes of this signaling pathway (AMPK, ADIPOR1, ADIPOR2, LKB1, CAMKK $\beta, C P T 1 A, C P T 1 B, P G C-1 \alpha, C D 36$, and ACC1) were differentially expressed between the Large White and Min pigs. Western blot analysis further confirmed that LKB1/CaMKK2-AMPK-ACC1-CPT1A axis dominates the activity of AMPK signaling pathway. Statistical analyses revealed that AMPK signaling pathway activity clearly varied among the two pig breeds. Based on these results, we concluded that the activation of the AMPK signaling pathway plays a positive role in reducing IMF deposition in pigs.
\end{abstract}

Keywords: AMPK signaling pathway; pig; intramuscular fat; data mining 


\section{Introduction}

As one of the most important domesticated animals for agricultural production, pigs provide many meat products for humans [1]. In modern society, pork quality has had an increasing influence on consumer acceptance and initial purchasing decisions. Consumers are interested in several major pork quality traits, including meat color, $\mathrm{pH}$ value, water holding capacity, and intramuscular fat (IMF) content, which are becoming increasingly important from an economic perspective [2,3]. Skeletal muscle is a heterogeneous tissue that consists of different types of myofibers, connective tissue, vascular tissue, nervous tissue, and IMF [4]. IMF is a major meat quality trait in pigs, and its content is directly associated with the sensory qualities, flavor, juiciness, tenderness, and nutritional quality of pork $[5,6]$. In recent decades, several studies have focused on the relationship between IMF and pork quality [7-10].

Famous lean pig breeds, such as Large White, Landrace, and Duroc, have lower IMF contents and reduced meat quality due to the intensive selection processes used to improve pork productivity. However, many excellent indigenous breeds are distributed in China, such as the Jinhua, Laiwu, Meishan, and Min, and they have higher IMF contents and better meat quality than the lean breeds [11-16]. Thus, it will be beneficial to reveal the molecular mechanisms of IMF deposition by comparing gene expression between lean and indigenous Chinese pig breeds.

With the rapid development of microarray and RNA-seq technologies in the last few decades, researchers are now able to study many differentially expressed genes (DEGs) simultaneously in a given tissue. To date, many studies concerning meat quality traits and gene expression in pigs have been reported [17-19]. Fortunately, the relevant datasets have been deposited and stored in the National Center for Biotechnology Information (NCBI) Gene Expression Omnibus (GEO) database and are freely accessible to researchers worldwide. However, few studies have focused on integrating and reanalyzing these datasets, which contain valuable clues regarding important porcine economic traits. Thus, by integrating and reanalyzing these datasets, we can provide significant insights into the molecular changes associated with IMF deposition.

In this study, we integrated and reanalyzed three original expression profiles from the GEO database based on a current popular differential gene expression analysis method. We found that the AMPK pathway plays a critical role in IMF deposition. We further validated this pathway through the use of quantitative real-time reverse transcription-polymerase chain reaction (qRT-PCR) arrays in the Large White and Min pig breeds.

\section{Materials and Methods}

\subsection{GEO Data Collection}

The gene expression profiles GSE24192, GSE75045, and GSE99092 [12,20,21] were downloaded from the GEO database. The GSE24192 dataset contained six samples, which included three Large White longissimus dorsi (LD) samples and three Northeastern Indigenous (Min) LD samples. The GSE75045 dataset contained six samples, which included three Large White LD samples and three Wannanhua LD samples. The GSE99092 dataset contained six samples, which included three Large White LD samples and three Wei LD samples. In the present study, Large White was set as the experimental group, the indigenous Chinese pig breeds were set as the control group.

\subsection{Identification of DEGs}

The limma package from Bioconductor and the online tool iDEP (https: / github.com/gexijin/ iDEP) were used to identify DEGs for the selected gene expression profile datasets [22]. A $p$-value less than 0.05 and $\left|\log _{\text {Fold Change(FC) }}\right| \geq 1$ were regarded as the cutoff thresholds for DEGs. 


\subsection{Signaling Pathway Enrichment Analysis of DEGs}

To analyze the functions of the DEGs, we performed a Kyoto Encyclopedia of Genes and Genomes (KEGG) pathway analysis of the DEGs using the online tool Kobas 3.0 [23]. A p-value less than 0.05 was considered statistically significant. ClusterProfiler was used for the statistical analysis and visualization of the functional profiles of the DEGs in the GEO datasets and qRT-PCR arrays [24]. TBtools was used to construct the Venn diagrams of the KEGG pathways for the DEGs in the three GEO datasets.

\subsection{Animals and Tissue Collection}

Three sows each from the Min and Large White breeds were used in this study. The Min pig is an excellent indigenous breed from northeastern China, and it has an IMF content higher than that of Large White pigs [12]. The pigs used in this study were obtained from the Institute of Animal Husbandry Research, Heilongjiang Academy of Agricultural Sciences (Harbin, China). The pigs were raised for 180 days under the same conditions. When the pigs were slaughtered, the LD muscle was collected between the 10th and 12th ribs from the carcasses. All tissue samples were divided into two groups; one group was quickly frozen immediately after collection and stored at $-80^{\circ} \mathrm{C}$ until use in qRT-PCR arrays, and the other group was stored at $4{ }^{\circ} \mathrm{C}$ for the determination of IMF content. All animal procedures were performed according to the University Committee on the Use and Care of Animals at Jilin University (approval ID: 201706030).

\subsection{Determination of IMF Content}

In the present study, the IMF content was measured in each LD sample by the Soxhlet extraction method with petroleum ether [25].

\subsection{RNA Extraction and Quantitative Real-Time Reverse Transcription-Polymerase Chain Reaction (Qrt-PCR) Arrays}

Total RNA from the LD was isolated from approximately $200 \mathrm{mg}$ of frozen tissue using TRIzol- $\mathrm{A}^{+}$ (TIANGEN, Beijing, China) following the manufacturer's instructions. The BioRT cDNA First Strand Synthesis Kit (Bioer Technology, Hangzhou, China) was used to synthesize first-strand cDNA. Subsequently, the expression levels of the target genes were analyzed on an $\mathrm{iQ}^{\mathrm{TM}} 5$ real-time PCR detection system (Bio-Rad, USA). A BioEasy SYBR Green I Real Time PCR kit (Bioer Technology) was used according to the manufacturer's instructions to detect each sample in triplicate. The primers used for the qRT-PCR arrays are listed in Table S1. The gene IDs from the selected pathways were obtained from the KEGG database (Table S2).

\subsection{Western Blot Analysis}

Protein samples from the LD of Large White $(n=3)$ and Min $(n=3)$ were separated by $10 \%$ SDS-PAGE gels and transferred electrophoretically onto polyvinylidene fluoride (PVDF) membranes (Millipore, Boston, MA, USA). Western blot was performed with rabbit anti-AMPK alpha 1 polyclonal antibody (1:1000, Bioss, Beijing, China), rabbit anti-LKB1 polyclonal antibody (1:1000, Bioss), rabbit anti-CaMKK2 polyclonal antibody (1:1000, Bioss), rabbit anti-CPT1A polyclonal antibody (1:1000, Bioss), and rabbit anti-ACC1 polyclonal antibody (1:1000, WUHAN SANYING) as the primary antibodies and Horseradish peroxidase (HRP)-conjugated goat anti-rabbit antibody as the second antibody. Rabbit anti- $\beta$-actin polyclonal antibody (1:8000, Bioss) was used as an internal control. Signals were detected using the SuperSignal WestPico Chemiluminescent Substrate Kit (Thermo Fisher Scientific) according to the manufacturer's instructions. 


\subsection{Statistical Analysis of the Qrt-PCR Array Results}

In the present study, the Large White pigs were set as the experimental group and the Min pigs were set as the control group. GraphPad Prism 6.01 (GraphPad Software, San Diego, CA, USA) was used for analyzing our results. Student's $t$-tests were used to compare the control and experimental groups. For all comparisons, ${ }^{*} p<0.05,{ }^{* *} p<0.01,{ }^{* * *} p<0.001$ and ${ }^{* * *} p<0.0001$ were considered significant differences. The $2^{-\Delta C T}$ method was used to calculate the $\mathrm{Ct}$ values from the qRT-PCR array data. The limma package was used to identify the significant DEGs of the qRT-PCR arrays between different groups [22]. TBtools was used to draw heatmaps of the qRT-PCR arrays (https://github.com/CJ-Chen/TBtools). The online tool KEGG Mapper was used to draw the colored map of DEGs (https:/ / www.kegg.jp/kegg/mapper.html). The STRING database was used to predict protein interactions and construct the network for DEGs [26]. The protein-protein interaction (PPI) network was visualized by Cytoscape [27].

\section{Results}

\subsection{Identification of DEGs in GEO Datasets}

According to the cutoff threshold ( $p<0.05$ and $\left.\left|\log _{\mathrm{FC}}\right| \geq 1\right)$, in GSE24192, 1237 DEGs were identified in the LD of Large White pigs when compared with the indigenous Chinese breeds, and they included 877 upregulated genes and 360 downregulated genes. In GSE75045, a total of 2582 DEGs were identified in the LD of Large White pigs, and they included 1096 upregulated genes and 1486 downregulated genes. Finally, in GSE99092, a total of 1822 DEGs were identified in the LD of Large White pigs, and they included 809 upregulated genes and 1013 downregulated genes.

\subsection{Pathway Enrichment of DEGs in GEO Datasets}

The KEGG pathway enrichment results (Figure 1D,E; Tables 1-3) yielded no shared pathways among the downregulated DEGs of Large White pigs in the three GEO datasets. In contrast, the AMPK signaling pathway (ssc04152), the peroxisome proliferator-activated receptor (PPAR) signaling pathway (ssc03320), fat digestion and absorption (ssc04975), fatty acid metabolism (ssc01212), metabolic pathways (ssc01100), and biosynthesis of amino acids (ssc01230) were among the upregulated DEGs in Large White pigs in the three GEO datasets. The AMPK signaling pathway may represent a novel pathway for regulating IMF deposition in pigs.

Table 1. KEGG pathway enrichment of the DEGs in the Large White pigs from GSE24912.

\begin{tabular}{lccc}
\hline Pathway ID & Name & Gene Count & $p$-Value \\
\hline & Upregulated DEGs & & \\
\hline ssc04145 & Phagosome & 36 & $1.66 \times 10^{-22}$ \\
ssc01100 & Metabolic pathways & 87 & $2.06 \times 10^{-18}$ \\
ssc00100 & Steroid biosynthesis & 6 & $3.08 \times 10^{-5}$ \\
ssc00330 & Arginine and proline metabolism & 8 & $4.48 \times 10^{-5}$ \\
ssc04062 & Chemokine signaling pathway & 15 & $5.27 \times 10^{-5}$ \\
ssc00590 & Arachidonic acid metabolism & 9 & $5.59 \times 10^{-5}$ \\
ssc01230 & Biosynthesis of amino acids & 9 & $8.49 \times 10^{-5}$ \\
ssc04923 & Regulation of lipolysis in adipocytes & 8 & $1.32 \times 10^{-4}$ \\
ssc04060 & Cytokine-cytokine receptor interaction & 16 & $1.92 \times 10^{-4}$ \\
ssc00010 & Glycolysis/gluconeogenesis & 8 & $2.24 \times 10^{-4}$ \\
ssc04810 & Regulation of actin cytoskeleton & 15 & $2.75 \times 10^{-4}$ \\
ssc04390 & Hippo signaling pathway & 12 & $2.98 \times 10^{-4}$ \\
ssc00592 & alpha-Linolenic acid metabolism & 5 & $4.30 \times 10^{-4}$ \\
ssc03320 & PPAR signaling pathway & 8 & $4.72 \times 10^{-4}$ \\
ssc04152 & AMPK signaling pathway & 10 & $9.76 \times 10^{-4}$ \\
ssc04975 & Fat digestion and absorption & 5 & $2.28 \times 10^{-3}$ \\
ssc00071 & Fatty acid degradation & 5 & $4.66 \times 10^{-3}$ \\
ssc01212 & Fatty acid metabolism & 5 & $7.78 \times 10^{-3}$ \\
\hline
\end{tabular}


Table 1. Cont.

\begin{tabular}{lccc}
\hline Pathway ID & Name & Gene Count & $p$-Value \\
\hline \multicolumn{4}{c}{ Downregulated DEGs } \\
\hline ssc00190 & Oxidative phosphorylation & 17 & $1.67 \times 10^{-13}$ \\
ssc01100 & Metabolic pathways & 38 & $5.02 \times 10^{-10}$ \\
ssc01210 & 2-Oxocarboxylic acid metabolism & 4 & $5.24 \times 10^{-5}$ \\
ssc04024 & cAMP signaling pathway & 10 & $5.68 \times 10^{-5}$ \\
ssc01230 & Biosynthesis of amino acids & 5 & $7.29 \times 10^{-4}$ \\
ssc04960 & Aldosterone-regulated sodium reabsorption & 4 & $9.76 \times 10^{-4}$ \\
ssc04931 & Insulin resistance & 6 & $1.03 \times 10^{-3}$ \\
ssc00220 & Arginine biosynthesis & 3 & $1.33 \times 10^{-3}$ \\
ssc04923 & Regulation of lipolysis in adipocytes & 4 & $2.79 \times 10^{-3}$ \\
ssc00400 & Phenylalanine, tyrosine, and tryptophan biosynthesis & 2 & $3.14 \times 10^{-3}$ \\
ssc03320 & PPAR signaling pathway & 4 & $5.59 \times 10^{-3}$ \\
ssc04920 & Adipocytokine signaling pathway & 4 & $5.86 \times 10^{-3}$ \\
ssc00250 & Alanine, aspartate, and glutamate metabolism & 3 & $6.59 \times 10^{-3}$ \\
\hline
\end{tabular}

A

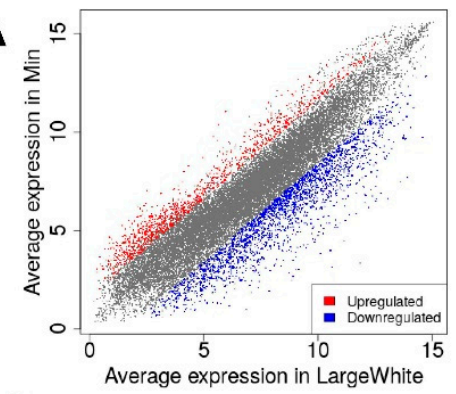

B

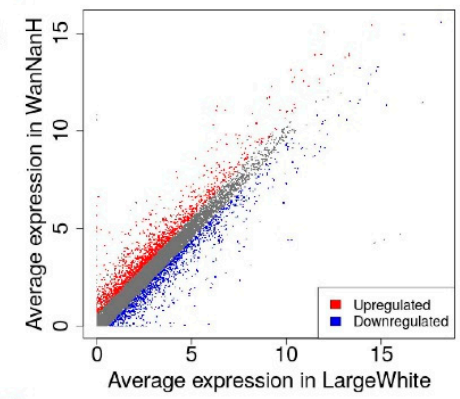

C

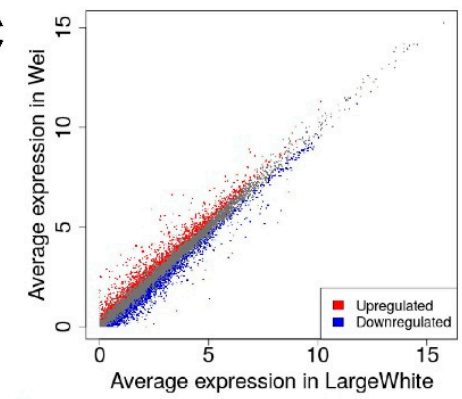

D

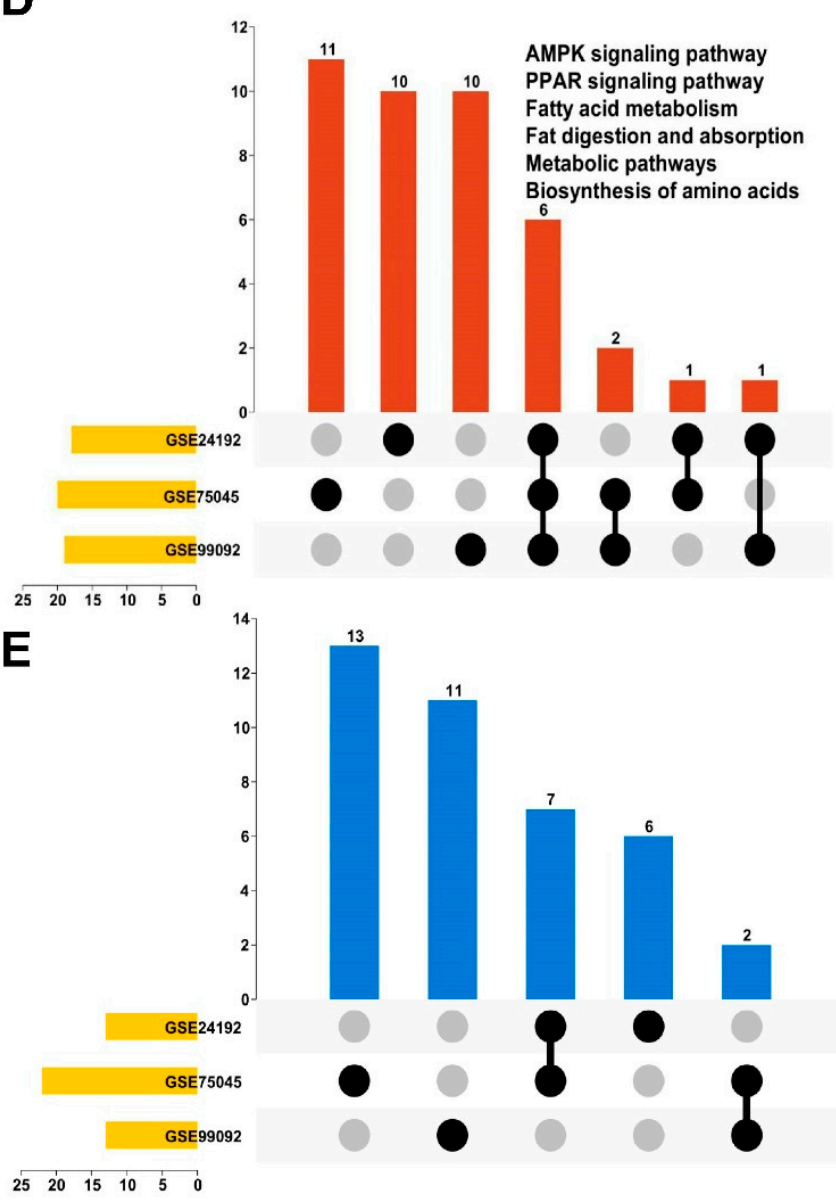

Figure 1. Data mining results for the three Gene Expression Omnibus (GEO) datasets. Scatter plot of differentially expressed genes (DEGs) in (A) GES24192, (B) GSE75045, and (C) GSE99092. (D) Venn diagrams of the Kyoto Encyclopedia of Genes and Genomes (KEGG) pathways for the upregulated genes in the three GEO datasets. The six shared pathways (AMPK signaling pathway, the peroxisome proliferator-activated receptor (PPAR) signaling pathway, fat digestion and absorption, fatty acid metabolism, metabolic pathways, and biosynthesis of amino acids) are listed in the figure. (E) Venn diagrams of the KEGG pathways for the downregulated genes in the three GEO datasets. 
Table 2. KEGG pathway enrichment of the DEGs in the Large White pigs from GSE75045.

\begin{tabular}{|c|c|c|c|}
\hline Pathway ID & Name & Gene Count & $p$-Value \\
\hline \multicolumn{4}{|c|}{ Upregulated DEGs } \\
\hline ssc04922 & Glucagon signaling pathway & 18 & $2.68 \times 10^{-7}$ \\
\hline ssc04910 & Insulin signaling pathway & 20 & $5.21 \times 10^{-6}$ \\
\hline ssc00010 & Glycolysis/gluconeogenesis & 13 & $9.46 \times 10^{-6}$ \\
\hline ssc01230 & Biosynthesis of amino acids & 14 & $1.18 \times 10^{-5}$ \\
\hline ssc01200 & Carbon metabolism & 14 & $5.35 \times 10^{-4}$ \\
\hline ssc04152 & AMPK signaling pathway & 14 & $1.01 \times 10^{-3}$ \\
\hline ssc00500 & Starch and sucrose metabolism & 8 & $2.01 \times 10^{-3}$ \\
\hline ssc00760 & Nicotinate and nicotinamide metabolism & 6 & $2.10 \times 10^{-3}$ \\
\hline ssc04974 & Protein digestion and absorption & 10 & $2.29 \times 10^{-3}$ \\
\hline ssc04911 & Insulin secretion & 9 & $4.71 \times 10^{-3}$ \\
\hline ssc04931 & Insulin resistance & 12 & $4.82 \times 10^{-3}$ \\
\hline ssc00051 & Fructose and mannose metabolism & 6 & $6.50 \times 10^{-3}$ \\
\hline ssc01100 & Metabolic pathways & 67 & $8.00 \times 10^{-3}$ \\
\hline ssc00620 & Pyruvate metabolism & 6 & $8.50 \times 10^{-3}$ \\
\hline $\operatorname{ssc} 04022$ & cGMP-PKG signaling pathway & 14 & $9.21 \times 10^{-3}$ \\
\hline ssc04015 & Rap1 signaling pathway & 16 & $9.32 \times 10^{-3}$ \\
\hline ssc00030 & Pentose phosphate pathway & 5 & $9.47 \times 10^{-3}$ \\
\hline ssc01212 & Fatty acid metabolism & 7 & $1.37 \times 10^{-2}$ \\
\hline $\operatorname{ssc} 03320$ & PPAR signaling pathway & 6 & $4.81 \times 10^{-2}$ \\
\hline ssc04975 & Fat digestion and absorption & 4 & $4.83 \times 10^{-2}$ \\
\hline \multicolumn{4}{|c|}{ Downregulated DEGs } \\
\hline ssc01100 & Metabolic pathways & 127 & $1.26 \times 10^{-9}$ \\
\hline ssc00071 & Fatty acid degradation & 16 & $1.62 \times 10^{-7}$ \\
\hline ssc01212 & Fatty acid metabolism & 16 & $2.91 \times 10^{-7}$ \\
\hline $\operatorname{ssc} 03320$ & PPAR signaling pathway & 16 & $2.16 \times 10^{-5}$ \\
\hline ssc00190 & Oxidative phosphorylation & 23 & $2.84 \times 10^{-5}$ \\
\hline ssc04146 & Peroxisome & 18 & $5.44 \times 10^{-5}$ \\
\hline ssc04260 & Cardiac muscle contraction & 15 & $1.18 \times 10^{-4}$ \\
\hline ssc00640 & Propanoate metabolism & 9 & $1.86 \times 10^{-4}$ \\
\hline ssc00620 & Pyruvate metabolism & 10 & $3.69 \times 10^{-4}$ \\
\hline ssc00280 & Valine, leucine, and isoleucine degradation & 11 & $5.68 \times 10^{-4}$ \\
\hline ssc01200 & Carbon metabolism & 17 & $1.05 \times 10^{-3}$ \\
\hline ssc00480 & Glutathione metabolism & 10 & $1.14 \times 10^{-3}$ \\
\hline ssc00561 & Glycerolipid metabolism & 10 & $2.15 \times 10^{-3}$ \\
\hline ssc00270 & Cysteine and methionine metabolism & 9 & $4.87 \times 10^{-3}$ \\
\hline ssc00250 & Alanine, aspartate, and glutamate metabolism & 8 & $5.33 \times 10^{-3}$ \\
\hline ssc00062 & Fatty acid elongation & 5 & $7.17 \times 10^{-3}$ \\
\hline ssc04261 & Adrenergic signaling in cardiomyocytes & 16 & $1.20 \times 10^{-2}$ \\
\hline $\operatorname{ssc} 04810$ & Regulation of actin cytoskeleton & 21 & $1.53 \times 10^{-2}$ \\
\hline ssc00061 & Fatty acid biosynthesis & 4 & $1.53 \times 10^{-2}$ \\
\hline ssc04920 & Adipocytokine signaling pathway & 10 & $1.82 \times 10^{-2}$ \\
\hline $\operatorname{ssc} 00400$ & Phenylalanine, tyrosine and tryptophan biosynthesis & 3 & $1.88 \times 10^{-2}$ \\
\hline ssc01230 & Biosynthesis of amino acids & 9 & $4.78 \times 10^{-2}$ \\
\hline
\end{tabular}

Table 3. KEGG pathway enrichment of the DEGs in the Large White pigs from GSE99092.

\begin{tabular}{lccc}
\hline Pathway ID & Name & Gene count & $p$-Value \\
\hline & Upregulated DEGs & & \\
\hline ssc01200 & Carbon metabolism & 17 & $5.04 \times 10^{-7}$ \\
ssc01100 & Metabolic pathways & 68 & $3.05 \times 10^{-6}$ \\
ssc00071 & Fatty acid degradation & 8 & $1.72 \times 10^{-4}$ \\
ssc01212 & Fatty acid metabolism & 8 & $2.37 \times 10^{-4}$ \\
ssc00280 & Valine, leucine, and isoleucine degradation & 8 & $3.73 \times 10^{-4}$ \\
ssc00640 & Propanoate metabolism & 6 & $5.48 \times 10^{-4}$ \\
ssc01210 & 2-Oxocarboxylic acid metabolism & 5 & $8.14 \times 10^{-4}$ \\
ssc00630 & Glyoxylate and dicarboxylate metabolism & 5 & $2.26 \times 10^{-3}$ \\
ssc00350 & Tyrosine metabolism & 5 & $6.61 \times 10^{-3}$ \\
ssc00620 & Pyruvate metabolism & 5 & $1.08 \times 10^{-2}$ \\
ssc00061 & Fatty acid biosynthesis & 3 & $1.32 \times 10^{-2}$ \\
ssc03320 & PPAR signaling pathway & 6 & $2.76 \times 10^{-2}$ \\
ssc00190 & Oxidative phosphorylation & 9 & $3.24 \times 10^{-2}$ \\
ssc04920 & Adipocytokine signaling pathway & 6 & $3.37 \times 10^{-2}$ \\
ssc00360 & Phenylalanine metabolism & 3 & $3.52 \times 10^{-2}$ \\
ssc01230 & Biosynthesis of amino acids & 6 & $3.82 \times 10^{-2}$ \\
ssc04152 & AMPK signaling pathway & 9 & $3.83 \times 10^{-2}$ \\
ssc04975 & Fat digestion and absorption & 3 & $4.38 \times 10^{-2}$ \\
ssc00380 & Tryptophan metabolism & 4 & $4.55 \times 10^{-2}$ \\
\hline
\end{tabular}


Table 3. Cont.

\begin{tabular}{lccc}
\hline Pathway ID & Name & Gene count & $p$-Value \\
\hline & Downregulated DEGs & & \\
\hline ssc04666 & Fc gamma R-mediated phagocytosis & 11 & $1.61 \times 10^{-3}$ \\
ssc04130 & SNARE interactions in vesicular transport & 7 & $2.63 \times 10^{-3}$ \\
ssc04512 & ECM-receptor interaction & 9 & $4.05 \times 10^{-3}$ \\
ssc00100 & Steroid biosynthesis & 5 & $4.94 \times 10^{-3}$ \\
ssc04974 & Protein digestion and absorption & 9 & $7.22 \times 10^{-3}$ \\
ssc04810 & Regulation of actin cytoskeleton & 15 & $2.87 \times 10^{-2}$ \\
ssc00310 & Lysine degradation & 6 & $3.41 \times 10^{-2}$ \\
ssc00260 & Glycine, serine, and threonine metabolism & 5 & $4.09 \times 10^{-2}$ \\
ssc00410 & beta-Alanine metabolism & 4 & $4.29 \times 10^{-2}$ \\
ssc04330 & Notch signaling pathway & 5 & $5.34 \times 10^{-2}$ \\
ssc00230 & Purine metabolism & 12 & $4.38 \times 10^{-2}$ \\
ssc00280 & Valine, leucine, and isoleucine degradation & 5 & $4.77 \times 10^{-2}$ \\
ssc00330 & Arginine and proline metabolism & 5 & $4.77 \times 10^{-2}$ \\
\hline
\end{tabular}

\subsection{IMF Content of LD Muscles in the Two Pigs}

As shown in Figure 2, the Min pigs had significantly higher IMF content than the Large White pigs.

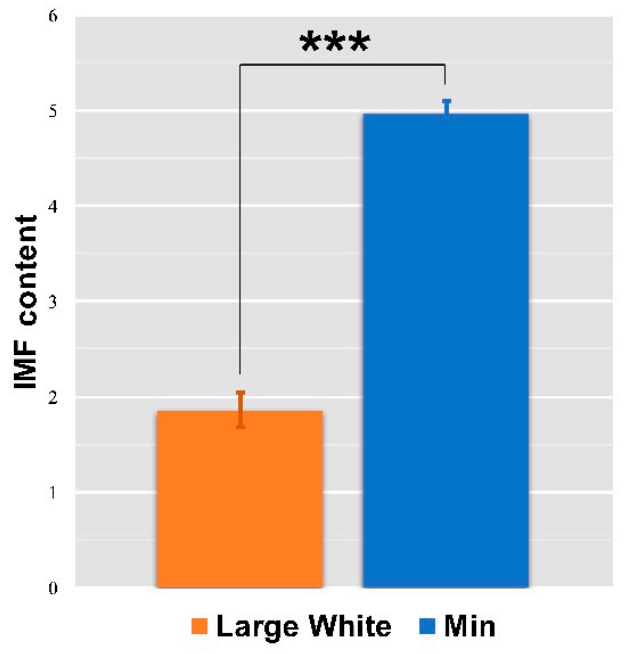

Figure 2. Detection of the IMF content in the LD muscles of Large White and Min pigs. Data represent the means $\pm \operatorname{SEM}(n=3){ }^{* * *} p<0.001$.

\subsection{Validation of the AMPK Signaling Pathway in the LD Muscles of the Two Pig Breeds}

The AMPK signaling pathway (ssc04152) consists of 117 genes (Table S2). In this study, 114 of these genes were validated via qRT-PCR array. Of them, 40 genes were differentially expressed in the Large White LD; 22 were upregulated and 18 were downregulated. The qRT-PCR results for the AMPK signaling pathway are shown in Figures 3-5, Tables 4 and 5. A heatmap of the AMPK signaling pathway is presented in Figure 3A, indicating that the expression patterns of the DEGs in the AMPK signaling pathway among the Large White and Min breeds show significant differences. Figure 3B shows a colored map of the AMPK signaling pathway in the LD of Large White pigs. Figure 4 shows a PPI network of 14 upregulated genes in the LD muscle of Large White pigs, and it contains 14 nodes and 36 edges. The most significant 10 node degree genes are SLC2A4, PGC-1 $\alpha, L K B 1, A M P K$, LIPE, CD36, CaMKK2, FOXO3, FOXO1, and CPT1B (Table 5). Moreover, based on the results of the colored map and PPI network, 10 genes in the AMPK signaling pathway (AMPK, ADIPOR1, ADIPOR2, $L K B 1, C a M K K \beta, C P T 1 A, C P T 1 B, P G C-1 \alpha, C D 36$, and $A C C 1)$ were selected as key hub genes, and their expression patterns are presented in Figure 5 . These hub genes are associated with fatty acid oxidation, lipid oxidation, and fatty acid metabolic processes. In addition, the protein expression levels of AMPK, LKB1, CaMKK2, CPT1A, and ACC1 were examined in the LD muscle of the Min and Large White pigs by Western blot analysis. The protein expression levels of AMPK, LKB1, CaMKK2, and CPT1A were 
higher in the Large White group than that the Min group, ACC1 showed low expression level in the LD muscle of Large White pigs (Figure 6). Taken together, these results show that the AMPK signaling pathway is more active in the Large White breed than the Min breeds.

A

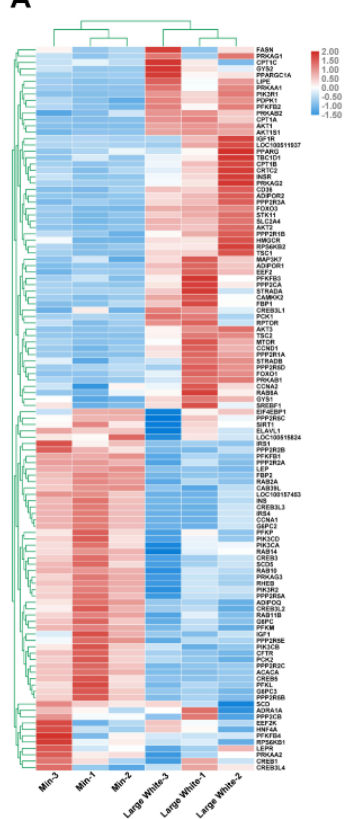

B

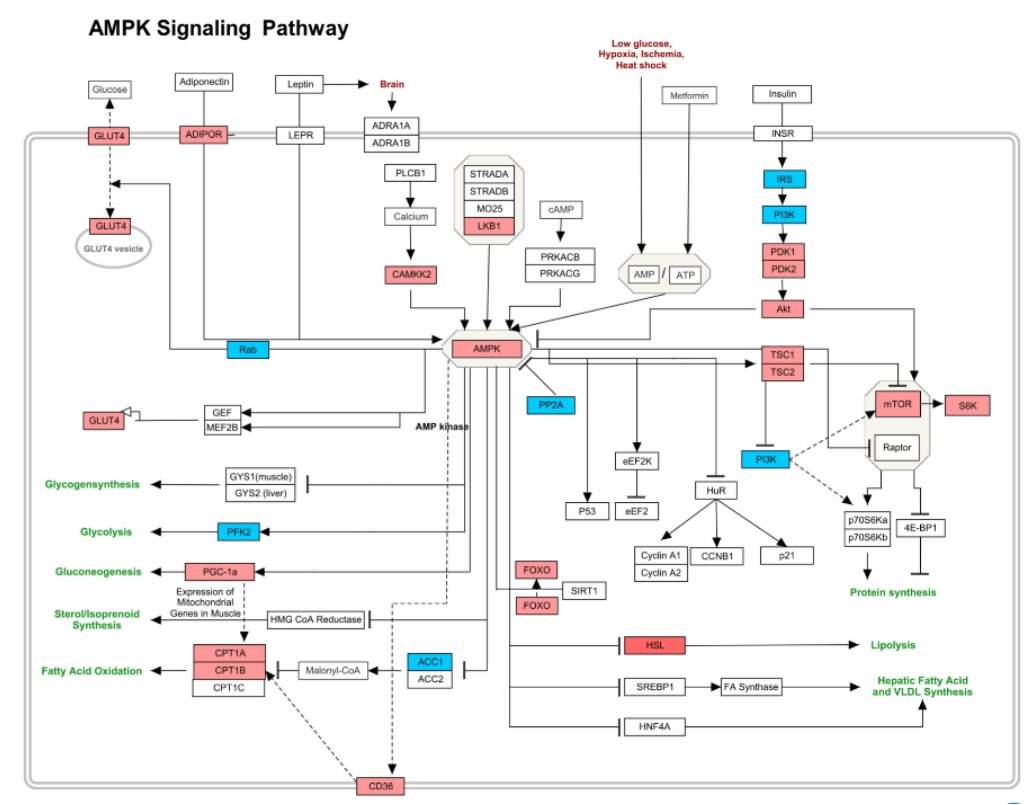

Figure 3. qRT-PCR array results in two pig breeds. (A) Heatmap of all qRT-PCR array genes. (B) Colored map of the AMPK signaling pathway. Upregulated and downregulated genes are indicated by red and blue, respectively.

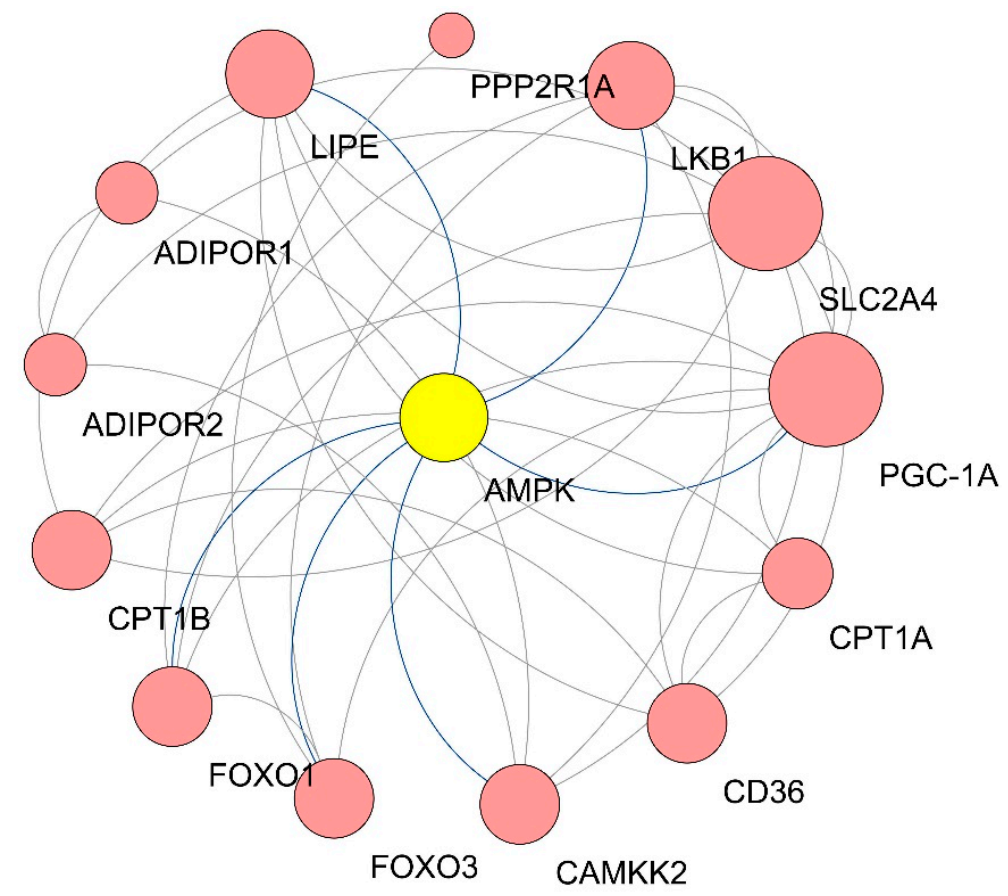

Figure 4. PPI network for the upregulated genes in the AMPK signaling pathway. The nodes represent the proteins (genes); the edges represent the interaction of proteins (genes). 


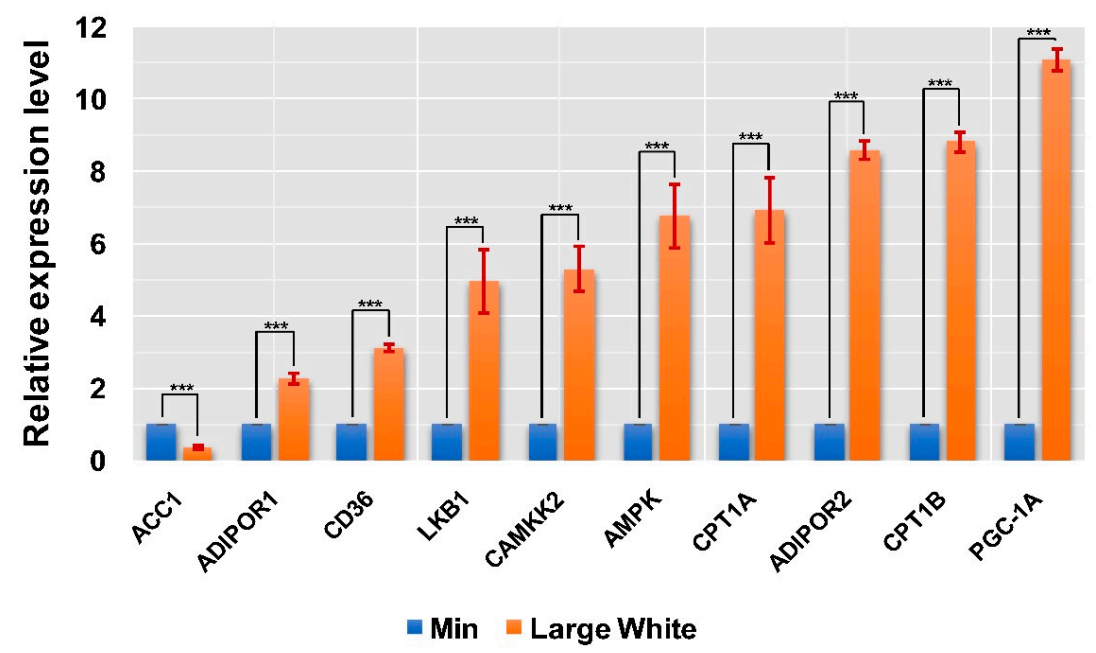

Figure 5. Relative expression levels of ten key hub genes in the AMPK signaling pathway in two pig breeds. All data are shown as the means $\pm \operatorname{SEM}(n=3),{ }^{* * *} p<0.001$.

Table 4. qRT-PCR array results for the AMPK signaling pathway (Large White-Min).

\begin{tabular}{|c|c|c|c|}
\hline Gene Symbol & Fold Change & $p$-Value & Regulation \\
\hline CD36 & 3.189283629 & $7.67 \times 10^{-3}$ & Up \\
\hline PGC-1A & 11.14850152 & $4.46 \times 10^{-2}$ & Up \\
\hline AKT2 & 3.156554305 & $3.62 \times 10^{-3}$ & Up \\
\hline AKT1 & 7.868832108 & $3.43 \times 10^{-5}$ & Up \\
\hline CPT1B & 8.890764573 & $3.93 \times 10^{-2}$ & $\mathrm{Up}$ \\
\hline ADIPOR2 & 8.509277729 & $7.67 \times 10^{-3}$ & Up \\
\hline PPP2R1A & 6.599066891 & $1.04 \times 10^{-2}$ & Up \\
\hline СРТ1A & 6.846403313 & $8.26 \times 10^{-4}$ & Up \\
\hline FOXO1 & 5.397575689 & $3.18 \times 10^{-2}$ & Up \\
\hline LIPE & 6.924041605 & $1.87 \times 10^{-2}$ & Up \\
\hline$L K B 1$ & 4.901757799 & $7.41 \times 10^{-3}$ & $\mathrm{Up}$ \\
\hline FOXO3 & 3.639771136 & $1.49 \times 10^{-4}$ & Up \\
\hline$M T O R$ & 4.068698015 & $2.35 \times 10^{-2}$ & $\mathrm{Up}$ \\
\hline ADIPOR1 & 2.245141118 & $3.62 \times 10^{-3}$ & Up \\
\hline RPS6KB2 & 3.361252687 & $4.11 \times 10^{-2}$ & $\mathrm{Up}$ \\
\hline AKT3 & 5.250417157 & $2.42 \times 10^{-2}$ & Up \\
\hline AMPK & 6.699341927 & $4.11 \times 10^{-2}$ & $\mathrm{Up}$ \\
\hline PDPK1 & 1.981200539 & $7.58 \times 10^{-3}$ & $\mathrm{Up}$ \\
\hline TSC2 & 2.740754696 & $7.67 \times 10^{-3}$ & Up \\
\hline$S L C 2 A 4$ & 9.440463793 & $1.01 \times 10^{-2}$ & $\mathrm{Up}$ \\
\hline CAMKK2 & 5.359797456 & $2.16 \times 10^{-2}$ & Up \\
\hline TSC1 & 8.141086731 & $1.08 \times 10^{-2}$ & $\mathrm{Up}$ \\
\hline PFKM & -5.001312186 & $5.39 \times 10^{-3}$ & Down \\
\hline$F B P 2$ & -5.808487321 & $1.08 \times 10^{-2}$ & Down \\
\hline$A C C 1$ & -2.601477756 & $1.86 \times 10^{-2}$ & Down \\
\hline$R A B 2 A$ & -2.652531932 & $3.07 \times 10^{-3}$ & Down \\
\hline PFKFB1 & -6.096200009 & $1.47 \times 10^{-2}$ & Down \\
\hline$P P P 2 R 2 A$ & -4.510811417 & $3.62 \times 10^{-3}$ & Down \\
\hline IRS1 & -8.500540176 & $1.87 \times 10^{-2}$ & Down \\
\hline CREB3 & -5.026439516 & $1.03 \times 10^{-2}$ & Down \\
\hline$P P P 2 R 5 A$ & -5.729220232 & $1.53 \times 10^{-2}$ & Down \\
\hline$P P P 2 R 5 B$ & -3.011595315 & $7.67 \times 10^{-3}$ & Down \\
\hline PFKL & -2.467192832 & $2.29 \times 10^{-2}$ & Down \\
\hline PIK3R2 & -3.841154966 & $2.35 \times 10^{-2}$ & Down \\
\hline PPP2R5E & -1.634192954 & $3.77 \times 10^{-2}$ & Down \\
\hline CREB5 & -1.953383525 & $1.08 \times 10^{-2}$ & Down \\
\hline G6PC3 & -2.621247554 & $3.18 \times 10^{-2}$ & Down \\
\hline$R A B 11 B$ & -4.129252447 & $3.58 \times 10^{-2}$ & Down \\
\hline РІКЗСВ & -2.137748295 & $4.37 \times 10^{-2}$ & Down \\
\hline PIK3CD & -3.600875922 & $4.88 \times 10^{-2}$ & Down \\
\hline
\end{tabular}


Table 5. Summary for the PPI network of 14 upregulated genes in the AMPK signaling pathway.

\begin{tabular}{cc}
\hline Gene Symbol & Degree \\
\hline SLC2A4 & 9 \\
PGC-1 $\alpha$ & 9 \\
LKB1 & 6 \\
AMPK & 6 \\
LIPE & 6 \\
CD36 & 5 \\
CAMKK2 & 5 \\
FOXO3 & 5 \\
FOXO1 & 5 \\
CPT1B & 5 \\
CPT1A & 4 \\
ADIPOR2 & 3 \\
ADIPOR1 & 3 \\
PPP2R1A & 1 \\
\hline Top ten degree genes are shown in bold.
\end{tabular}

A

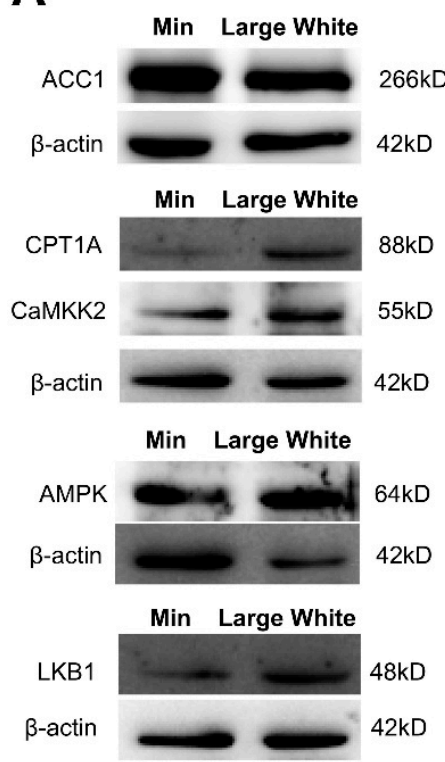

B

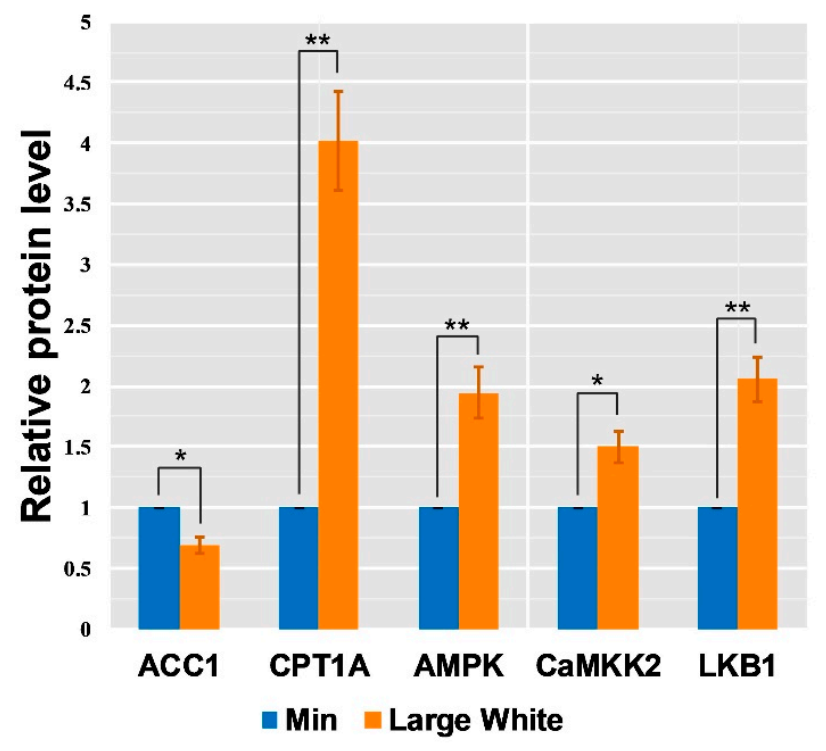

Figure 6. Relative expression levels of AMPK, LKB1, CaMKK2, CPT1A, and ACC1 proteins in the AMPK signaling pathway in two pig breeds. All data are shown as the means $\pm \operatorname{SEM}(n=3),{ }^{*} p<0.05$, ** $p<0.01$. Representative western blots (A) and quantitative densitometry analysis (B) of AMPK, LKB1, CaMKK2, CPT1A, and ACC1 protein levels are shown in the LD muscle of Large White and Min pigs.

\subsection{GO Enrichment of DEGs in Qrt-PCR Arrays}

The biological processes encoded by upregulated genes were involved in fatty acid oxidation, lipid oxidation, and fatty acid metabolic processes, while the biological processes encoded by the downregulated genes were involved in carbohydrate metabolic processes, including glucose, hexose, and monosaccharide metabolism, as well as hexose and monosaccharide catabolism (Figure 7). These results indicate that compared with the LD of Min pigs, the LD of Large White pigs consumes more fat for energy metabolism than carbohydrates. 
A Sig Go terms of Up-regulated gene-BP

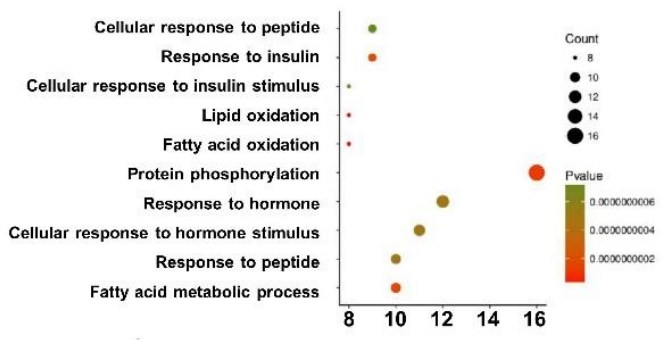

B Sig Go terms of Up-regulated gene-CC

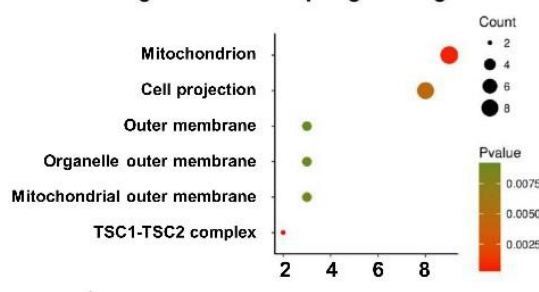

C Sig Go terms of Up-regulated gene-MF

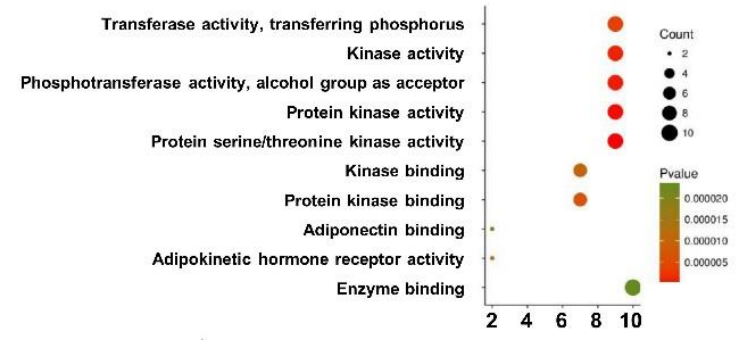

D Sig Go terms of Down-regulated gene-BP

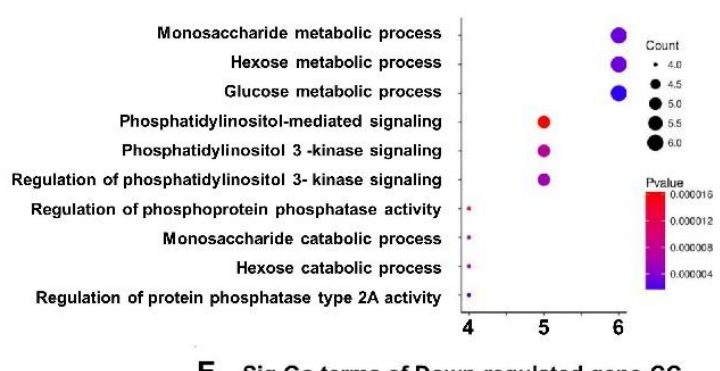

E Sig Go terms of Down-regulated gene-CC
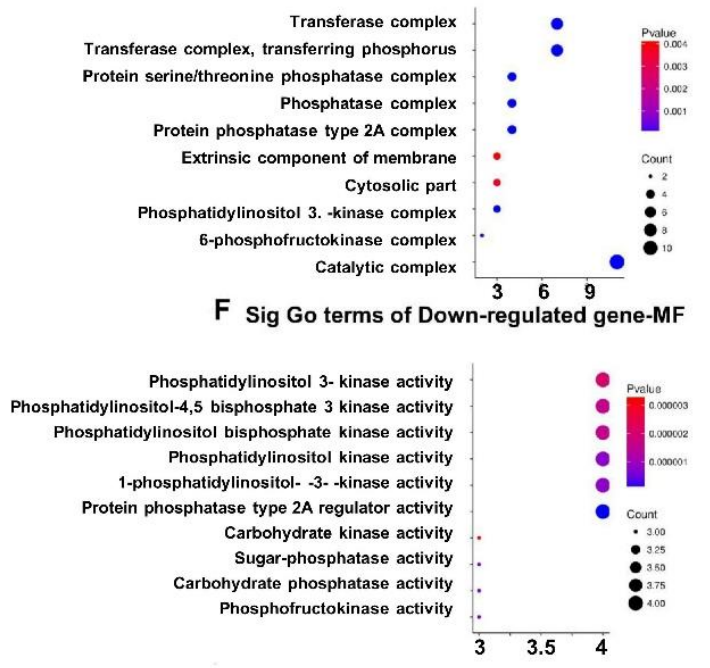

Figure 7. GO terms include three complementary biological roles, Biological Process (BP), Molecular Function (MF), and Cellular Component (CC), for the DEGs in the qRT-PCR array. BP for upregulated (A) and downregulated (D) genes. CC for upregulated (B) and downregulated (E) genes. MF for upregulated $(\mathbf{C})$ and downregulated $(\mathbf{F})$ genes.

\section{Discussion}

In the modern pork industry, the IMF content is an important trait that is positively associated with pork quality and in demand by consumers. As a complex meat trait, IMF deposition in the LD muscle is regulated by multiple genes and pathways. In this study, by integrating and reanalyzing three gene expression profiles, we compared the pathways related to IMF deposition in the LD muscle of Large White pigs with those of indigenous breeds. Several candidate signaling pathways were found, and the expression patterns of genes in the AMPK pathway in pigs were validated by qRT-PCR arrays in subsequent experiments.

The AMPK signaling pathway plays critical roles in controlling both glucose and lipid metabolism. $A M P K$ is the central gene of the AMPK signaling pathway and a heterotrimeric enzyme with $\alpha, \beta$, and $\gamma$ subunits. Once activated, $A M P K$ promotes lipid oxidation and glucose uptake, inhibits lipid synthesis and decreases IMF contents [28]. Accordingly, the activity of $A M P K$ is inversely correlated with IMF accumulation. In the present study, $A M P K$ was highly expressed in the LD muscle of Large White pigs, which has a lower IMF content than Min pigs. This result is consistent with several previous reports demonstrating that the expression levels of $A M P K$ are higher in the low-IMF-content skeletal muscle of cattle and sheep [29-31], suggesting that AMPK plays a positive role in reducing the IMF content in pigs.

As a member of the adipocytokines, adiponectin plays crucial roles in whole-body energy homeostasis by stimulating AMPK. ADIPOR1 and ADIPOR2 are two major receptors for adiponectin and play key roles in metabolic pathways that regulate glucose and lipid metabolism, inflammation, 
and oxidative stress [32]. ADIPOR1 and ADIPOR2 mediate the metabolic actions of adiponectin by activating $A M P K$ and $P P A R \alpha$, respectively. This activation leads to increased fatty acid oxidation and glucose uptake in mice [33-35]. Moreover, muscle-specific disruption of ADIPOR1 inhibits the increase in intracellular $\mathrm{Ca}^{2+}$ concentration and reduces the activation of calmodulin-dependent kinase $\beta(C a M K K \beta)$ and $A M P K$ by adiponectin. Consistent with these previously reported results, ADIPOR1 and ADIPOR2 were both upregulated in the LD muscle of Large White pigs in the present study, suggesting that these two genes may account for the low IMF accumulation in pigs. Interestingly, two upstream kinases of $A M P K$, the tumor suppressor $L K B 1$ and $\mathrm{Ca}^{2+} / C a M K K \beta$, which participate in the phosphorylation and activation of $A M P K$, were simultaneously highly expressed in the LD muscle of Large White pigs. AMPK can be activated via two distinct mechanisms, LKB1 encodes a serine-threonine kinase that directly phosphorylates and activates AMPK, and CaMKK $\beta$ can form a complex with and activate AMPK through their kinase domains in skeletal muscle [36-39]. Consistent with these previous findings, our results suggest that $L K B 1$ and $C a M K K \beta$ play critical roles in reducing the IMF content in pigs by activating the expression of $A M P K$.

Furthermore, $A M P K$ plays a central role in controlling lipid metabolism by regulating the downstream acetyl-CoA carboxylase (ACC1) and carnitine palmitoyltransferase 1 (CPT1) pathways. $C P T 1$, a rate-limiting enzyme of mitochondrial fatty acid $\beta$-oxidation, is closely associated with fat deposition. Additionally, CPT1A and CPT1B, two common CPT1 subtypes in mammals, play prominent roles in fatty acid oxidation and lipid accumulation in humans, chickens, and pigs [40-42]. Moreover, according to the KEGG database, $C P T 1 A$ and $C P T 1 B$ are involved in the AMPK signaling pathway, implying that these genes participate in the mediation of fatty acid oxidation. In addition, the $A C C 1$ gene encodes acetyl-CoA carboxylase $(A C C)$, which is the rate-limiting enzyme responsible for the de novo synthesis of fatty acids [43]. As a target gene of the AMPK signaling pathway, the activity of $A C C 1$ is inhibited by $A M P K$. Similarly, an increase in activity of $A C C 1$ can also inhibit the expression of $C P T 1$ and fatty acid oxidation in skeletal muscles [44-46]. Consistent with these previous results, both $C P T 1 A$ and $C P T 1 B$ were highly expressed and $A C C 1$ was significantly downregulated in the LD muscle of Large White pigs, suggesting that the AMPK-ACC1-CPT1 pathway was positively associated with a decrease in fatty acid synthesis and IMF deposition in pigs.

In addition to $C P T 1$, the fatty acid transporter fatty acid translocase/cluster of differentiation 36 (FAT/CD36) has also been found to regulate FA oxidation in skeletal muscle of human and mice [47,48]. $F A T / C D 36$ has been identified as contributing to fatty acid transport and oxidation in mice [49-51]. In our results, FAT/CD36 was highly expressed in the LD muscle of Large White pigs, implying that the expression of this gene has a negative effect on IMF deposition in Large White pigs. Interestingly, the peroxisome proliferator-activated receptor gamma coactivator 1-alpha (PPARGC1A, PGC-1 $\alpha$ ) was also involved in the activation of the CPT1 gene [52]. PGC-1 $\alpha$ plays an important role in glucose and fatty acid metabolism and has a negative relationship with the IMF content in pigs [53-55]. In this study, PGC-1 $\alpha$ presented a high expression level in the LD of Large White, suggesting that this gene exerts a negative effect on IMF deposition in pigs. Additionally, the protein expression of AMPK, LKB1, CaMKK2, CPT1A, and ACC1 were further analyzed with Western blot. In our results, four proteins (AMPK, LKB1, CaMKK2, and CPT1A) showed higher expression in the LD muscle of Large White pigs than that in Min pigs, and ACC1 had a low protein expression level in the Large White group, indicating that the AMPK signaling pathway is more active at the protein level and that the oxidative degradation of fatty acids is stronger in the Large White group. In summary, the above results suggest that the activation of the AMPK signaling pathway reduces the IMF content in the LD muscle of Large White pigs.

\section{Conclusions}

In conclusion, this study illustrates that the accumulation of IMF in Large White pigs is related to activation of the AMPK signaling pathway. The relatively high expression of genes in the AMPK pathway may represent one of the more significant features of pigs with artificially lean meat. Our 
results are also helpful for interpreting the different molecular mechanisms of IMF deposition between lean and fat pig breeds.

Supplementary Materials: The following are available online at http:/ /www.mdpi.com/2076-2615/9/4/137/s1, Table S1: Primers used in this study, Table S2: Summary of the AMPK signaling pathway from the KEGG database.

Author Contributions: H.Y. and H.O. conceived and designed the experiments; C.Y. and D.P. performed the experiments; C.L., A.X. and P.H. collected the samples; and C.Y. and D.P. wrote the paper.

Funding: This research was funded by the Special Funds for Cultivation and Breeding of New Transgenic Organisms of China (No. 2016ZX08006001 \& 2016ZX08006003).

Acknowledgments: This work was supported by the Special Funds for Cultivation and Breeding of New Transgenic Organisms of China (No. 2016ZX08006001 \& 2016ZX08006003). The funders had no role in the study design, data collection and analysis, decision to publish, or preparation of the manuscript. We thank Wentao Wang and Xinmiao He (Heilongjiang Academy of Agricultural Sciences) for their help in sample collection. We thank American Journal Experts (https:/ / www.aje.com/) for its linguistic assistance during the preparation of this manuscript.

Conflicts of Interest: The authors declare no conflicts of interest.

\section{References}

1. Puig-Oliveras, A.; Ramayo-Caldas, Y.; Corominas, J.; Estelle, J.; Perez-Montarelo, D.; Hudson, N.J.; Casellas, J.; Folch, J.M.; Ballester, M. Differences in Muscle Transcriptome among Pigs Phenotypically Extreme for Fatty Acid Composition. PLoS ONE 2014, 9, e99720. [CrossRef] [PubMed]

2. Font-I-Furnols, M.; Tous, N.; Esteve-Garcia, E.; Gispert, M. Do all the consumers accept marbling in the same way? The relationship between eating and visual acceptability of pork with different intramuscular fat content. Meat Sci. 2012, 91, 448-453. [CrossRef] [PubMed]

3. Nonneman, D.J.; Shackelford, S.D.; King, D.A.; Wheeler, T.L.; Wiedmann, R.T.; Snelling, W.M.; Rohrer, G.A. Genome-wide association of meat quality traits and tenderness in swine1,2. J. Anim. Sci. 2013, 91, 4043-4050. [CrossRef] [PubMed]

4. Larzul, C.; Lefaucheur, L.; Ecolan, P.; Gogué, J.; Talmant, A.; Sellier, P.; Le Roy, P.; Monin, G. Phenotypic and genetic parameters for longissimus muscle fiber characteristics in relation to growth, carcass, and meat quality traits in large white pigs. J. Anim. Sci. 1997, 75, 3126. [CrossRef] [PubMed]

5. Wang, X.W.; Ding, R.R.; Quan, J.P.; Yang, L.X.; Yang, M.; Zheng, E.Q.; Liu, D.W.; Cai, G.Y.; Wu, Z.F.; Yang, J. Genome-wide association analysis reveals genetic loci and candidate genes associated with intramuscular fat in Duroc pigs. Front. Agric. Sci. Eng. 2017, 4, 335-341. [CrossRef]

6. Won, S.; Jung, J.; Park, E.; Kim, H.; Kim, H.B. Identification of genes related to intramuscular fat content of pigs using genome-wide association study. Asian-Australas. J. Anim. Sci. 2017, 31, 157-162. [CrossRef]

7. Brewer, M.; Zhu, L.; McKeith, F. Marbling effects on quality characteristics of pork loin chops: Consumer purchase intent, visual and sensory characteristics. Meat Sci. 2001, 59, 153-163. [CrossRef]

8. Lim, K.S.; Lee, K.T.; Park, J.E.; Chung, W.H.; Jang, G.W.; Choi, B.H.; Hong, K.C.; Kim, T.H. Identification of differentially expressed genes in longissimus muscle of pigs with high and low intramuscular fat content using RNA sequencing. Anim. Genet. 2016, 48, 166-174. [CrossRef]

9. Suzuki, K.; Irie, M.; Kadowaki, H.; Shibata, T.; Kumagai, M.; Nishida, A. Genetic parameter estimates of meat quality traits in Duroc pigs selected for average daily gain, longissimus muscle area, backfat thickness, and intramuscular fat content. J. Anim. Sci. 2005, 83, 2058-2065. [CrossRef]

10. Van Laack, R.L.; Stevens, S.G.; Stalder, K.J. The influence of ultimate $\mathrm{pH}$ and intramuscular fat content on pork tenderness and tenderization. J. Anim. Sci. 2001, 79, 392. [CrossRef] [PubMed]

11. Dai, F.W.; Feng, D.Y.; Cao, Q.Y.; Ye, H.; Zhang, C.M.; Xia, W.G.; Zuo, J.J. Developmental differences in carcass, meat quality and muscle fibre characteristics between the Landrace and a Chinese native pig. S. Afr. J. Anim. Sci. 2009, 39, 267-273. [CrossRef]

12. Gao, Y.; Zhang, Y.; Jiang, H.; Xiao, S.; Wang, S.; Ma, Q.; Sun, G.; Li, F.; Deng, Q.; Dai, L.; et al. Detection of differentially expressed genes in the longissimus dorsi of Northeastern Indigenous and Large White pigs. Genet. Mol. Res. 2011, 10, 779-791. [CrossRef] 
13. Wang, Y.; Ma, C.; Sun, Y.; Li, Y.; Kang, L.; Jiang, Y. Dynamic transcriptome and DNA methylome analyses on longissimus dorsi to identify genes underlying intramuscular fat content in pigs. BMC Genom. 2017, $18,780$. [CrossRef] [PubMed]

14. Wu, T.; Zhang, Z.; Yuan, Z.; Lo, L.J.; Chen, J.; Wang, Y.; Peng, J. Distinctive Genes Determine Different Intramuscular Fat and Muscle Fiber Ratios of the longissimus dorsi Muscles in Jinhua and Landrace Pigs. PLoS ONE 2013, 8, e53181. [CrossRef] [PubMed]

15. Xiong, X.; Liu, X.; Zhou, L.; Yang, J.; Yang, B.; Ma, H.; Xie, X.; Huang, Y.; Fang, S.; Xiao, S.; et al. Genome-wide association analysis reveals genetic loci and candidate genes for meat quality traits in Chinese Laiwu pigs. Mamm Genome 2015, 26, 181-190. [CrossRef]

16. Yang, S.; Li, X.; Li, K.; Fan, B.; Tang, Z. A genome-wide scan for signatures of selection in Chinese indigenous and commercial pig breeds. BMC Genet. 2014, 15, 7. [CrossRef]

17. Li, B.; Weng, Q.; Dong, C.; Zhang, Z.; Li, R.; Liu, J.; Jiang, A.; Li, Q.; Jia, C.; Wu, W.; et al. A Key Gene, PLIN1, Can Affect Porcine Intramuscular Fat Content Based on Transcriptome Analysis. Genes 2018, 9, 194. [CrossRef]

18. Pena, R.N.; Quintanilla, R.; Manunza, A.; Gallardo, D.; Casellas, J.; Amills, M. Application of the microarray technology to the transcriptional analysis of muscle phenotypes in pigs. Anim. Genet. 2014, 45, 311-321. [CrossRef]

19. Tao, X.; Liang, Y.; Yang, X.; Pang, J.; Zhong, Z.; Chen, X.; Yang, Y.; Zeng, K.; Kang, R.; Lei, Y.; et al. Transcriptomic profiling in muscle and adipose tissue identifies genes related to growth and lipid deposition. PLoS ONE 2017, 12, e0184120. [CrossRef]

20. Li, X.; Zhou, J.; Liu, L.; Qian, K.; Wang, C. Identification of genes in longissimus dorsi muscle differentially expressed between Wannanhua and Yorkshire pigs using RNA-sequencing. Anim. Genet. 2016, 47, 324-333. [CrossRef]

21. Xu, J.; Wang, C.; Jin, E.; Gu, Y.; Li, S. Identification of differentially expressed genes in longissimus dorsi muscle between Wei and Yorkshire pigs using RNA sequencing. Genes Genom. 2017, 40, 413-421. [CrossRef]

22. Smyth, G.K. limma: Linear Models for Microarray Data. Bioinform. Comput. Biol. Solut. Using R Bioconductor 2005, 397-420. [CrossRef]

23. Xie, C.; Mao, X.; Huang, J.; Ding, Y.; Wu, J.; Dong, S.; Kong, L.; Gao, G.; Li, C.-Y.; Wei, L. KOBAS 2.0: A web server for annotation and identification of enriched pathways and diseases. Acids Res. 2011, 39, W316-W322. [CrossRef]

24. Yu, G.; Wang, L.-G.; Han, Y.; He, Q.-Y. clusterProfiler: An R Package for Comparing Biological Themes Among Gene Clusters. OMICS 2012, 16, 284-287. [CrossRef] [PubMed]

25. Supakankul, P.; Mekchay, S. Association of NLK polymorphisms with intramuscular fat content and fatty acid composition traits in pigs. Meat Sci. 2016, 118, 61-65. [CrossRef] [PubMed]

26. Szklarczyk, D.; Franceschini, A.; Wyder, S.; Forslund, K.; Heller, D.; Huerta-Cepas, J.; Simonovic, M.; Roth, A.; Santos, A.; Tsafou, K.P.; et al. STRING v10: Protein-protein interaction networks, integrated over the tree of life. Acids Res. 2014, 43, D447-D452. [CrossRef] [PubMed]

27. Shannon, P.; Markiel, A.; Ozier, O.; Baliga, N.S.; Wang, J.T.; Ramage, D.; Amin, N.; Schwikowski, B.; Ideker, T. Cytoscape: A Software Environment for Integrated Models of Biomolecular Interaction Networks. Genome Res. 2003, 13, 2498-2504. [CrossRef]

28. Carling, D. The AMP-activated protein kinase cascade-A unifying system for energy control. Biochem. Sci. 2004, 29, 18-24. [CrossRef]

29. Tong, J.; Zhu, M.J.; Underwood, K.R.; Hess, B.W.; Ford, S.P.; Du, M. AMP-activated protein kinase and adipogenesis in sheep fetal skeletal muscle and 3T3-L1 cells1. J. Anim. Sci. 2008, 86, 1296-1305. [CrossRef] [PubMed]

30. Underwood, K.; Means, W.; Zhu, M.; Ford, S.; Hess, B.; Du, M. AMP-activated protein kinase is negatively associated with intramuscular fat content in longissimus dorsi muscle of beef cattle. Meat Sci. 2008, 79, 394-402. [CrossRef]

31. Underwood, K.R.; Tong, J.; Zhu, M.J.; Shen, Q.W.; Means, W.J.; Ford, S.P.; Paisley, S.I.; Hess, B.W.; $\mathrm{Du}, \mathrm{M}$. Relationship between Kinase Phosphorylation, Muscle Fiber Typing, and Glycogen Accumulation inLongissimusMuscle of Beef Cattle with High and Low Intramuscular Fat. J. Agric. Chem. 2007, 55, 9698-9703. [CrossRef] [PubMed] 
32. Yamauchi, T.; Iwabu, M.; Okada-Iwabu, M.; Kadowaki, T. Adiponectin receptors: A review of their structure, function and how they work. Best Pract. Res. Clin. Endocrinol. Metab. 2014, 28, 15-23. [CrossRef] [PubMed]

33. Yamauchi, T.; Kamon, J.; Minokoshi, Y.; Ito, Y.; Waki, H.; Uchida, S.; Yamashita, S.; Noda, M.; Kita, S.; Ueki, K.; et al. Adiponectin stimulates glucose utilization and fatty-acid oxidation by activating AMP-activated protein kinase. Nat. Med. 2002, 8, 1288-1295. [CrossRef]

34. Yamauchi, T.; Nio, Y.; Maki, T.; Kobayashi, M.; Takazawa, T.; Iwabu, M.; Okada-Iwabu, M.; Kawamoto, S.; Kubota, N.; Kubota, T.; et al. Targeted disruption of AdipoR1 and AdipoR2 causes abrogation of adiponectin binding and metabolic actions. Nat. Med. 2007, 13, 332-339. [CrossRef] [PubMed]

35. Yoon, M.J.; Lee, G.Y.; Chung, J.-J.; Ahn, Y.H.; Hong, S.H.; Kim, J.B. Adiponectin Increases Fatty Acid Oxidation in Skeletal Muscle Cells by Sequential Activation of AMP-Activated Protein Kinase, p38 Mitogen-Activated Protein Kinase, and Peroxisome Proliferator-Activated Receptor. Diabetes 2006, 55, 2562-2570. [CrossRef]

36. Abbott, M.J.; Edelman, A.M.; Turcotte, L.P. CaMKK is an upstream signal of AMP-activated protein kinase in regulation of substrate metabolism in contracting skeletal muscle. Am. J. Physiol. Integr. Comp. Physiol. 2009, 297, R1724-R1732. [CrossRef]

37. Green, M.F.; Anderson, K.A.; Means, A.R. Characterization of the CaMKK $\beta$-AMPK Signaling Complex. Cell. Signal. 2011, 23, 2005-2012. [CrossRef]

38. Sakamoto, K.; McCarthy, A.; Smith, D.; A Green, K.; Hardie, D.G.; Ashworth, A.; Alessi, D.R. Deficiency of LKB1 in skeletal muscle prevents AMPK activation and glucose uptake during contraction. EMBO J. 2005, 24, 1810-1820. [CrossRef] [PubMed]

39. Zhou, L.; Deepa, S.S.; Etzler, J.C.; Ryu, J.; Mao, X.; Fang, Q.; Liu, D.D.; Torres, J.M.; Jia, W.; Lechleiter, J.D. Adiponectin activates AMPK in muscle cells via APPL1/LKB1- and PLC/Ca ${ }^{2+} / \mathrm{CaMKK}$-dependent pathways. J. Biol. Chem. 2009, 284, jbc-M109. [CrossRef] [PubMed]

40. Qiu, F.; Xie, L.; Ma, J.-E.; Luo, W.; Zhang, L.; Chao, Z.; Chen, S.; Nie, Q.; Lin, Z.; Zhang, X. Lower Expression of SLC27A1 Enhances Intramuscular Fat Deposition in Chicken via Down-Regulated Fatty Acid Oxidation Mediated by CPT1A. Front. Physiol. 2017, 8, 449. [CrossRef]

41. Zhang, Y.-F.; Yuan, Z.-Q.; Song, D.-G.; Zhou, X.-H.; Wang, Y.-Z. Effects of cannabinoid receptor 1 (brain) on lipid accumulation by transcriptional control of CPT1A and CPT1B. Anim. Genet. 2013, 45, 38-47. [CrossRef]

42. Kim, J.-Y.; Hickner, R.C.; Cortright, R.L.; Dohm, G.L.; Houmard, J.A. Lipid oxidation is reduced in obese human skeletal muscle. Am. J. Physiol. Metab. 2000, 279, E1039-E1044. [CrossRef] [PubMed]

43. Jones, J.E.C.; Esler, W.P.; Patel, R.; Lanba, A.; Vera, N.B.; Pfefferkorn, J.A.; Vernochet, C. Inhibition of Acetyl-CoA Carboxylase 1 (ACC1) and 2 (ACC2) Reduces Proliferation and De Novo Lipogenesis of EGFRvIII Human Glioblastoma Cells. PLoS ONE 2017, 12, e0169566. [CrossRef]

44. Alam, N.; Saggerson, E.D. Malonyl-CoA and the regulation of fatty acid oxidation in soleus muscle. Biochem. J. 1998, 334, 233-241. [CrossRef]

45. Saha, A.K.; Schwarsin, A.J.; Roduit, R.; Massé, F.; Kaushik, V.; Tornheim, K.; Prentki, M.; Ruderman, N.B. Activation of Malonyl-CoA Decarboxylase in Rat Skeletal Muscle by Contraction and the AMP-activated Protein Kinase Activator 5-Aminoimidazole-4-carboxamide-1- $\beta$-d-ribofuranoside. J. Boil. Chem. 2000, 275, 24279-24283. [CrossRef] [PubMed]

46. Scaglia, N.; Chisholm, J.W.; Igal, R.A. Inhibition of StearoylCoA Desaturase-1 Inactivates Acetyl-CoA Carboxylase and Impairs Proliferation in Cancer Cells: Role of AMPK. PLoS ONE 2009, 4, e6812. [CrossRef]

47. Schenk, S.; Horowitz, J.F. Coimmunoprecipitation of FAT/CD36 and CPT I in skeletal muscle increases proportionally with fat oxidation after endurance exercise training. Am. J. Physiol. Metab. 2006, 291, E254-E260. [CrossRef] [PubMed]

48. Smith, B.K.; Jain, S.S.; Rimbaud, S.; Dam, A.; Quadrilatero, J.; Bonen, A.; Holloway, G.P.; Ventura-Clapier, R.; Ventura-Clapier, R. FAT/CD36 is located on the outer mitochondrial membrane, upstream of long-chain acyl-CoA synthetase, and regulates palmitate oxidation. Biochem. J. 2011, 437, 125-134. [CrossRef] [PubMed]

49. Bonen, A.; Campbell, S.E.; Benton, C.R.; Chabowski, A.; Coort, S.L.M.; Han, X.-X.; Koonen, D.P.Y.; Glatz, J.F.C.; Luiken, J.J.F.P. Regulation of fatty acid transport by fatty acid translocase/CD36. Proc. Nutr. Soc. 2004, 63, 245-249. [CrossRef] [PubMed]

50. Campbell, S.E.; Tandon, N.N.; Woldegiorgis, G.; Bonen, A.; Luiken, J.J.F.P.; Glatz, J.F.C. A Novel Function for Fatty Acid Translocase (FAT)/CD36. J. Boil. Chem. 2004, 279, 36235-36241. [CrossRef] 
51. Ibrahimi, A.; Bonen, A.; Blinn, W.D.; Hajri, T.; Li, X.; Zhong, K.; Cameron, R.; Abumrad, N.A. Muscle-specific Overexpression of FAT/CD36 Enhances Fatty Acid Oxidation by Contracting Muscle, Reduces Plasma Triglycerides and Fatty Acids, and Increases Plasma Glucose and Insulin. J. Boil. Chem. 1999, 274, 26761-26766. [CrossRef]

52. Louet, J.F.; Hayhurst, G.; Gonzalez, F.J.; Girard, J.; Decaux, J.F. The coactivator PGC-1 is involved in the regulation of the liver carnitine palmitoyltransferase I gene expression by cAMP in combination with HNF4 alpha and cAMP-response element-binding protein (CREB). J. Biol. Chem. 2002, 277, 37991-38000. [CrossRef] [PubMed]

53. Beeson, C.C.; Beeson, G.C.; Buff, H.; Eldridge, J.; Zhang, A.; Seth, A.; Demcheva, M.; Vournakis, J.N.; Muise-Helmericks, R.C. Integrin-Dependent Akt1 Activation Regulates PGC-1 Expression and Fatty Acid Oxidation. J. Vasc. Res. 2012, 49, 89-100. [CrossRef] [PubMed]

54. Li, Q.; Wang, Z.; Zhang, B.; Lu, Y.; Yang, Y.; Ban, D.; Wu, C.; Zhang, H. Single Nucleotide Polymorphism Scanning and Expression of the Pig PPARGC1A Gene in Different Breeds. Lipids 2014, 49, 1047-1055. [CrossRef] [PubMed]

55. Yu, K.; Shu, G.; Yuan, F.; Zhu, X.; Gao, P.; Wang, S.; Wang, L.; Xi, Q.; Zhang, S.; Zhang, Y.; et al. Fatty Acid and Transcriptome Profiling of Longissimus Dorsi Muscles between Pig Breeds Differing in Meat Quality. Int. J. Boil. Sci. 2013, 9, 108-118. [CrossRef]

(C) 2019 by the authors. Licensee MDPI, Basel, Switzerland. This article is an open access article distributed under the terms and conditions of the Creative Commons Attribution (CC BY) license (http:/ / creativecommons.org/licenses/by/4.0/). 